\title{
INTEGRATION OF BUSINESS PROCESS MODELING IN PLANNING A GRADUATE PROGRAM IN DATA ANALYTICS
}

\author{
Jesse Smith $\mathrm{MBA}^{1 *} \quad$ Ann E. Stapleton $\mathrm{PhD}^{2 \dagger} \quad$ Cem \\ Canel PhD ${ }^{3 \ddagger}$
}

${ }^{1} 1$ Business Administration, Cameron School of Business, University of North Carolina Wilmington, Wilmington, NC, 28403, USA

${ }^{2}$ Department of Biology and Marine Biology, University of North Carolina Wilmington, NC 28403, USA

${ }^{3}$ Department of Information Systems and Operations Management, Cameron School of Business, University of North Carolina Wilmington, Wilmington, NC 28403, USA

\section{Correspondence}

Cem Canel PhD, Department of Information Systems and Operations Management, Cameron School of Business, University of North Carolina Wilmington, Wilmington, NC 28403, USA

Email: canelc@uncw.edu

\section{Present address}

* Department Head of Quality Control, The Roger Bacon Academy, Leland, NC 28451, USA

Funding information

\section{1 | INTRODUCTION}

Data analytics is one of the most popular job sectors of the 21st century. It is in high demand across industries and is severely lacking in needed talent Davenport and Patil (2012). In the current literature, this field is often referred 
to as business intelligence and analytics ( $\mathrm{BI}$ and $\mathrm{A}$ ) which describes a broad category of applications, technologies, architectures, and processes for gathering, storing, accessing, and analyzing data. Data analytics provides businesses with timely competitive information to utilize in decision-making Gupta et al. (2015). The McKinsey Global Institute reported in 2011 that there could be a severe shortage of 140,000 to 190,000 people with deep analytical skills by 2018 in the United States alone as well as 1.5 million managers and business analysts who can use big data to make effective decisions, innovate new product and service solutions, and improve and optimize business processes and performance Gupta et al. (2015). To compound this lack of talent, there is also the need for businesses to remain competitive which, as identified by the IBM Global CIO Study of 2011, 83 percent of CIOs responding to the survey identified $\mathrm{BI}$ and $\mathrm{A}$ as the top priority over the next several years Chiang et al. (2012). Wang reports that over 130 academic programs have started offering undergraduate and graduate degrees in business analytics or data science since 2007 Wang (2015) in order to fill the growing need for deep statistical analysis of ever-growing, highly variable "big data" sets which are also interdisciplinary by nature Jacobi et al. (2014). The difficulty of bringing together disciplinary-based faculty and students and melding individual objectives in a collaborative effort has been noted leading to the need for business process modeling in higher education to encourage communication and flexibility to changing market needs Bardecki (2015). In this paper, we explore the challenges facing universities as demand increases for interdisciplinary programs with problem-based curricula, with a specific focus on the growing market for data analytics skills Jacobi et al. (2014). To contribute to this effort, we conducted two levels of research to (1) identify skills needed to satisfy the analytics job market from a regional business perspective and (2) develop business process maps outlining current graduate program processes from the University perspective.

\section{2 | MARKET DEMAND AND ANALYTICS SKILLS}

Businesses are facing new challenges not only in the management of big data but also in the meaningful analysis of data, the latter of which requires a specific approach and unique set of skills. The Institute for Operations Research and Management Science (INFORMS) defines this specific approach as "business analytics" which facilitates the understanding of business objectives through reporting of data to analyze trends, creating predictive models for forecasting, and optimizing business processes for enhanced performance (Chiang et al., 2012). The depth of required knowledge to conduct data analytics is not trivial, it requires a relatively new, hybrid role first coined in 2008-that of a data scientist (Davenport and Patil, 2012). This position requires a broad combination of technical and business skills as well as multidisciplinary knowledge domains (Wang, 2015). Due to the scope of knowledge required for a data scientist, job descriptions and skill requirements are often obscure causing 64 percent of organizations in the U.S. to fail at meeting all of their expected analyzing data skills needed in the workplace according to American Management Association's 2013 report (Wang, 2015). INFORMS defines analytics as (1) descriptive - the use of data to find out what happened in the past, (2) predictive - the use of data to find out what could happen in the future, and (3) prescriptive - the use of data to prescribe the best course of action for the future (Chiang et al., 2012). These are described as the three perspectives of business decision-making, and it is acknowledged that there is a clear shortage of individuals with the capacity to handle this level of deep analytical thinking (Chiang et al., 2012). A recent survey reveals that while technical business intelligence skills are significant for the analytics professional, soft skills such as verbal and written communication skills, identifying key metrics for business growth, interpreting complex trends in data and working in teams are equally, if not more important (Gupta et al., 2015). 


\subsection{Research - Business Interviews}

Business interviews were conducted in the surrounding region where The University of North Carolina Wilmington (UNCW) is located. One of the main purposes of these interviews was to investigate the need for and desired skills of analytics professionals in a regional market in comparison to what is found in current literature. Fifteen semi-structured interviews were arranged in total, each averaging one hour in length over the course of two months. The interviews took place face-to-face at the business location with alternate mutually agreed locations chosen as needed. The businesses included in the research were chosen based on their industry connection to the field of analytics and their growth. Industry sectors ranged across manufacturing, clinical research, healthcare, banking, recruiting services, engineering consultancy, and software design. The interviews began with general introductions and learning more about the analytics needs of the business as well as the interviewee's role in the firm. It was explained that the University was proposing a new graduate degree in data analytics and asked what tools a graduate from such a program should have as well as what ideal function(s) they could perform if hired by the business. Table 11 provides a summary of noted tools as well as technical and soft skills that these businesses provide. In addition to the time it took to arrange the interviews,

TAB LE 1 Summary of Tools and Skills Indicated During Business Interviews

\begin{tabular}{|c|c|c|}
\hline Tools & Technical Skills & Soft Skills \\
\hline SAS & Statistics & Pacesetter \\
\hline $\mathrm{R}$ & Data Visualization & $\begin{array}{l}\text { Ability to teach and communicate well with } \\
\text { others, convey an idea }\end{array}$ \\
\hline Python & Ability to wrangle and formulate data & Ability to tell a story with data \\
\hline C & Knowledge of graph databases & Communicate risk \\
\hline SQL & ETL (extract, transform, load) background & Cultural fit \\
\hline Minitab & Solve real-world problems & Passion for solving problems \\
\hline $\begin{array}{l}\text { Amazon } \\
\text { Redshift }\end{array}$ & $\begin{array}{l}\text { Analytical data preparation; pull in, clean up, } \\
\text { summarize, maintain quality }\end{array}$ & Ability to take failure with unstructured data \\
\hline Excel & $\begin{array}{l}\text { Manipulate big data sets, marry up on the } \\
\text { same platform }\end{array}$ & Social skills (need finesse) \\
\hline Hadoop & Pattern recognition & Present in a concise manner \\
\hline Deep Learning & Ability to find holes in data & Provide accurate time estimation \\
\hline SPARK & Data wrangling - dealing with data gaps & Schedule and manage time effectively \\
\hline \multirow[t]{3}{*}{ Java } & Monetize data & Create additional knowledge \\
\hline & & Ability to support proposals with data \\
\hline & & $\begin{array}{l}\text { Think on two different wavelengths - wear } \\
\text { multiple hats }\end{array}$ \\
\hline
\end{tabular}

mostly via email, it took approximately fifteen hours to conduct the business interviews followed by approximately twenty hours of analysis for a total number of thirty-five hours. We concluded that the analytics market is strong in 
the local region surrounding the University and that the skill set desired was in line with that found in the literature. Ultimately, businesses need professionals who can interpret complex data and put it into a brief story that helps to drive business growth. Additional positive outcomes from these interviews included forming relationships with area businesses to benefit any future analytics graduate degree program(s), in the form of Advisory Board members and internship opportunities.

\subsection{1 | T-Shaped Professional Skills}

The consensus in literature and through the research conducted with regional businesses acknowledges that a true data scientist requires analytical skills, IT and programming skills, business and domain knowledge, and interpersonal skills to meet the needs in today's market (Jacobi et al., 2014). Additionally, analyzing data requires techniques that draw from various disciplines such as statistics and machine learning in computer science. The interaction of these across different disciplines and skills are captured in various iterations of the Data Science Venn Diagram, as seen in Figure 1. To accomplish the necessary level of both technical skills and ability to collaborate across the various departments of a

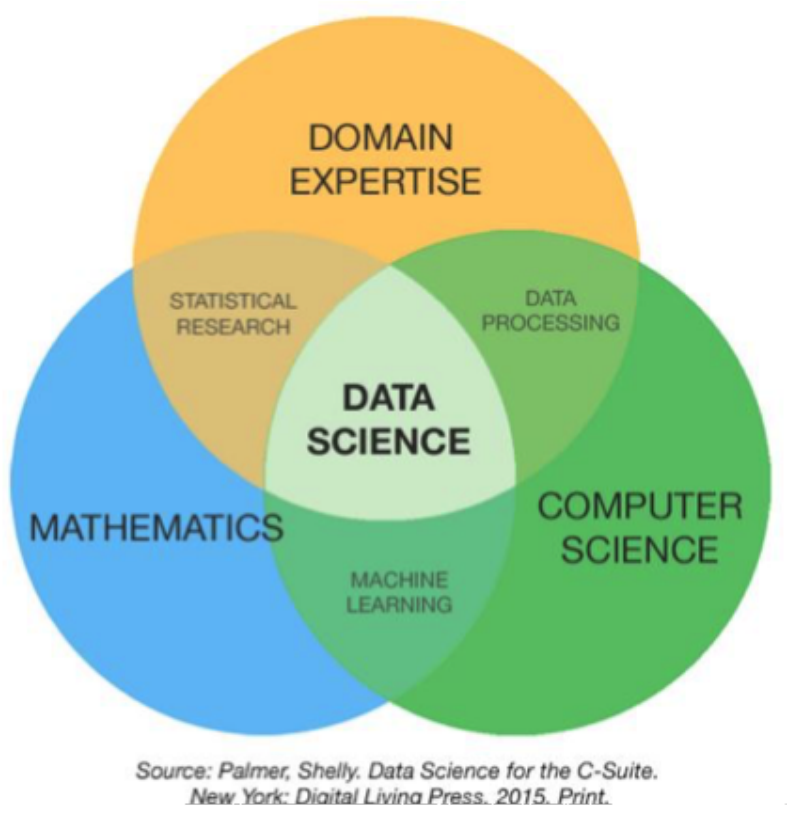

FIGURE 1 Data Science Venn Diagram (Palmer, 2015)

business requires that of a T-shaped person. T-shaped people have two kinds of characteristics to describe them: the vertical stroke of the "T" is depth of knowledge in a particular skill or system, and the horizontal stroke of the " $\mathrm{T}$ " is the capacity for collaboration across disciplines as seen in Figure 2 (Donofrio et al., 2010). Advocates of T-shaped people often mention that the breadth of knowledge and experience enables faster adaptation and role changes, in addition to better communication skills for teamwork in a multidisciplinary context (Donofrio et al., 2010). Professionals with these qualities are called versatilists who, in their numerous roles and experiences can apply their depth of skills to a rich scope of situations and challenges to implement cross-organizational insight to lead teams and fill competency gaps noa. 


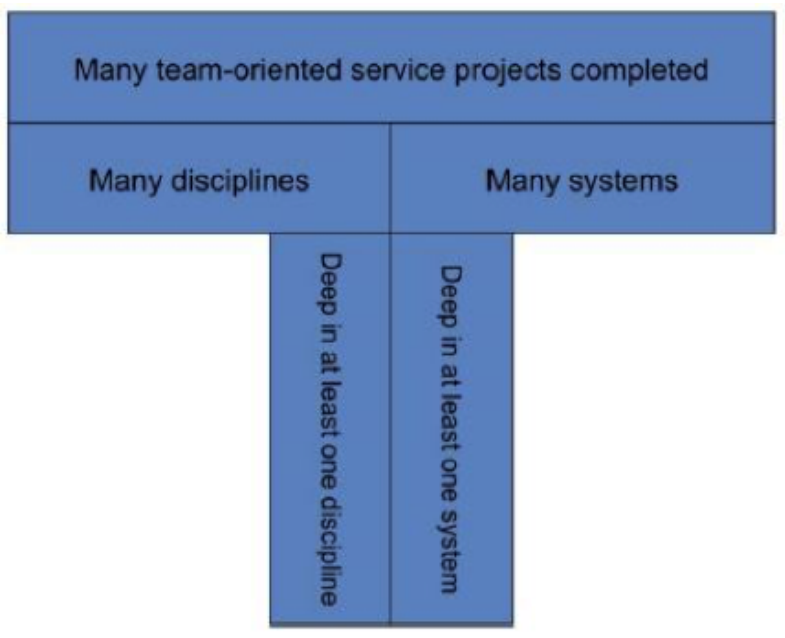

FIGURE 2 T-shaped Professionals: Combining deep knowledge and collaboration skills

\section{3 | INTERDISCIPLINARY PROGRAM AND CURRICULUM DESIGN}

The level of collaboration sought by businesses looking for analytics professionals with T-shaped skills requires integration across disciplines in Universities. The current traditional University model in which faculty are bound to disciplinary schools and departments poses multiple challenges, perhaps most importantly, lack of innovation in curriculum design due to disciplinary norms and differing perspectives causing issues with program evaluation and assessment Gantogtokh and Quinlan (2017). An additional challenge is providing a curriculum structure that is responsive to students from diverse academic backgrounds Bardecki (2015). These challenges can make it difficult to fulfill the necessary data analytics skills needed in the workplace which may lead to the reorganization and construction of knowledge beyond that of the traditions of the current academic disciplinary structure of graduate education Bardecki (2015); Leshner (2015). The following are characteristics indicated as key conditions for the success of interdisciplinary initiatives at universities Bardecki (2015):

- Inception as faculty initiative, rather than a top-down administrative approach,

- A fluid organization and flexible involvement,

- A supportive administration,

- Consistent yet flexible funding,

- A short reporting structure and ease of access to administration, and

- A core group of individuals serving as leaders of the interdisciplinary initiative.

One such program that has experienced successful integration across departments is the Masters of Applied Science program in Environmental Applied Science and Management (EnSciMan) at Ryerson University, a public university with 34,000 students located in Toronto, Canada. EnSciMan operates as a collaborative effort among its faculty in a horizontally-organized university-wide from outside the traditional academic departments and schools. All faculty in this program, except one cross-appointed faculty member, were hired by their respective disciplinary departments and continued to fulfill their responsibilities within their home departments and schools. The director of EnSciMan 
reports to the Dean of Graduate Studies. EnSciMan compensates departments, through its budget, for faculty who have opted to teach in the program Bardecki (2015). A second example is the development of a Health Informatics and Analytics graduate program at Florida International University; a series of challenges were addressed by actions such as new faculty hires and transfer of faculty between units Tremblay et al. (2016). Another major challenge in developing an interdisciplinary program, specifically an analytics program, is the lack of guidance in current literature on how to develop harmonized interdisciplinary curricula that produce data scientists with the necessary skills determined by the market. Jacobi et al. (2014) outline the process for finding and communicating a consensus about critical discipline skills to shape interdisciplinary curricula by first obtaining a community consensus from representatives of associations in the field. Secondly, discipline professionals evaluate the consensus skills according to workplace relevance. This stage requires assigning four values to each skill about curriculum integration Jacobi et al. (2014):

- Must - describes a skill that has to be part of the curriculum.

- Should - represents a high-priority skill that should be included if possible.

- Could - describes a skill which is considered desirable but not necessary.

- Won't - represents a skill that is currently less relevant from a professional's point of view but may be considered in the future.

Once community consensus and evaluation of the skills about workplace relevance has taken place, departments can then link their ranked skills with learning objectives to shape program curriculum and establish the formal structure of the program. The following factors are determined to build a successful interdisciplinary business intelligence and analytics program Giles (2015); Wang (2015):

- Developing new interdisciplinary courses by collaborating with other departments and industry experts,

- Aligning business intelligence and analytics course curricula with the skill set needed to ensure student employment and success in the workplace,

- Using real-world projects that allow student collaboration with industrial professionals to learn problem-solving skills, teamwork skills, and interpersonal skills,

- Curriculum that captures the union of statistics, quantitative methods, management information systems, and business savvy and,

- Strengthening faculty members' expertise in business analytics and intelligence and encouraging communication with local employers to stay abreast of trends.

\section{1 | Interdisciplinary Program Effectiveness and Evaluation}

After developing the learning objectives for an interdisciplinary program, the next step is to use these to evaluate the effectiveness of program curricula based on student outcomes as well as continued course relevance to business needs. However, it is noted that there remains a shortage of theoretical frameworks on how to evaluate students' learning effectiveness regarding skill acquisition from a business intelligence and analytics course and what experiences affect student engagement Wang (2015). Additionally, there is a concern of lack of flexibility in curriculum design due to university specific constraints and contingency factors Jacobi et al. (2014); Gantogtokh and Quinlan (2017). The Tennessee Colleges of Applied Technology notes that a key to the success of their multicampus institutions-which have an enrollment of 27,000 students-is the planning that links academic programs to strong employment sectors. Each campus has a Business and Industry Advisory Board including representatives from major employers, local governments, 
and others with an interest in economic development and education as well as experts with specific knowledge of the job sectors related to individual programs. This organizational structure ensures program evaluation from experts, which maintains a learning environment where students are provided the necessary skills to succeed in the workplace and thus find employment in their field after graduation Giles (2015). Job placement percentage is a primary benchmark and metric of program success for North Carolina State University's Masters of Science in Advanced Analytics program. Ensuring future employers have access to top analytics graduates and are aware of the value they are receiving is taken very seriously and results in 100 percent job placement with six-figure salaries Rappa. Programs tend to focus on feedback from faculty, current students, and industry experts; however, obtaining feedback from new graduates is another important source of information to use in program evaluation to ensure that expectations and objectives are met Wang (2015). Longitudinal studies that obtain graduates' opinions at different career stages can also help assess the success of interdisciplinary programs and provide evidence of adjustment and improvement of current curriculum design Bardecki (2015); Wang (2015) . A larger number of universities are also using learning outcomes assessments to drive continuous program improvement. Assessments can be used to gather and synthesize information concerning a student's learning to evaluate learning outcomes. These results can be utilized to continually drive the quality and effectiveness of the common core of a program Drost and Chaney (2014).

\subsection{Existing Analytics Programs}

When deciding what type of graduate analytics degree to offer at the university level and its management structure, various program options produce data scientists with the degree of analytics skills needed in the workplace. These choices typically depend on the resources at the given university and demand from the student population. A full-time Master's degree in data analytics can provide the right environment to cover the skills and knowledge necessary for students that have little or no prior business intelligence and analytics experience. An alternate approach would be to create analytics concentrations in existing MS Information Systems programs, which utilize already existing curriculum in technology, data management, business disciplines, and communication skills, and adds the necessary analytics coverage. Additional means of providing analytics knowledge would be to offer a graduate certificate program which can be used by various programs as a concentration such as in MBA programs to fulfill the need of equipping managers with the ability to make decisions based on analytics Chiang et al. (2012). Graduate certificates also offer flexibility to students who are employed and looking to expand their knowledge to remain competitive. Another key decision to make when starting a new analytics program is that of program format which is also dependent on resources and demand; program development at universities has a typical trajectory from re-branding to maturity Cegielski and Jones-Farmer (2016). Current programs are in full-time, part-time, and online formats and vary in some course credit hours and cost. A summary of existing and approved to start graduate analytics programs in the U.S. which are categorized into four groups including Master of Science in Analytics, Master of Science in Data Science, Master of Science in Business Analytics, and Other M.S. Tracks and Concentrations is available Rappa. These programs range in length from nine months to four years with nearly half offering a 12-month option. The graduate degree programs included in the listing maintained by Rappa (2017) are typically designed to attract analytically strong students, with undergraduate degrees in areas such as mathematics, science, computer science, and engineering Chiang et al. (2012). Existing programs such as EnSciMan and NC State University's Master of Science in Advanced Analytics program have goals of selecting a cohort of students to assure a broadly-based student body including a portion of students who have recently graduated with an undergraduate degree as well as those who have a range of work experience Bardecki (2015); Rappa. Although overcoming collaborative challenges between disciplines can be difficult, it is possible for a program to bring together disciplinary-based faculty and students from diverse backgrounds to offer cohesive, interdisciplinary programs that 
cross traditional boundaries Bardecki (2015). Integration and synergy among various disciplines can help cultivate the next generation of analytical thinkers who are both business and technically savvy Chiang et al. (2012).

\section{4 | BUSINESS PROCESS MODELING IN HIGHER EDUCATION}

Given the requirements that lead to a successful interdisciplinary graduate degree in data analytics and meet the needs of the current and ever-fluctuating job market, it is evident that traditional university models may face challenges. Clear lines of communication and a commitment to faculty-faculty interactions are imperative to for a successful and sustainable interdisciplinary graduate program Gantogtokh and Quinlan (2017). Additionally, the success of a university depends on its ability to ensure the necessary resources to achieve the main objective, which relies on the provision of knowledge and skills embodied in people and technologies Drăgan et al. (2014). When we closely examine how higher education institutions perform work, we find out that many of the work processes are based on old manual systems or unintegrated legacy student information systems. Process mapping is a primary tool that provides analysis of systems to help understand and improve work processes and achieve significant productivity and efficiency gains DeSantis and Laudato (2015). While mostly used in the business sector, Business Process Management (BPM) is a provider of tools and techniques used to manage business processes efficiently. A business process is a collection of related, structured activities or tasks that produce a specific service or product, in this case, a graduate program, and are part of a larger whole Elias et al. (2014). Process mapping can be an integral part of process improvement efforts and business process re-engineering (BPR) initiatives. Process improvement is appropriate when an institution is seeking relatively minor quality or efficiency improvements while BPR pursues radical rethinking of existing processes Abdous and $\mathrm{He}$ (2008). According to a recent study, higher education institutions have invested heavily in business process re-engineering to leverage information technology to improve services and reduce costs Abdous and $\mathrm{He}$ (2008). The adoption of business process improvement strategies and business process modeling in higher education institutions can help evaluate and improve procedures that are antiquated and inflexible to the needs of more complex programs such as that of an interdisciplinary analytics graduate degree Drăgan et al. (2014); Swanson and Hepner (2011).

\section{1 | Graduate Program Process Mapping Research}

We conducted research through three main methods including semi-structured interviews with university domain experts at the University, document analysis, and participation in faculty meetings to map the current business processes involved with starting and sustaining a new graduate program In the first method, we conducted a total of fifteen interviews with various university administrators who are involved in operations of graduate programs including university administration (i.e. Chancellor, Provost, and Deans), department chairs, graduate program directors, and various levels of graduate school staff. These interviews averaged one hour in length and took over three months to complete. The general topics covered included specific operations questions in regards to graduate programs as well as methods for starting a new interdisciplinary analytics degree. Follow-up interviews were scheduled with faculty most closely involved with the operations of graduate programs to review the on-going progress of the business process maps to ensure accuracy. In total, it took approximately twenty hours to conduct all interviews followed by an additional thirty hours of analysis. As the second method, we used document analysis to investigate the business processes. From the interviews, formal documents were obtained that are used in business processes at both the local and state university levels in regards to the operations of graduate programs. We obtained additional supporting documents and records about starting a new Professional Science Master's degree in Data Analytics that were contained in an 
electronic portfolio. These supporting documents helped to identify some of the business processes that were later mapped as part of the overall graduate program process. In total, analyses of these documents took about fifteen hours and were useful to complement the information obtained from the interviews. The third method of research involved participation in two faculty planning meetings led by the Dean of the Graduate School for those in support of starting and teaching courses in an analytics program. These meetings involved faculty from appropriate departments and schools including Mathematics and Statistics, Computer Science, Information Systems and Operations Management, and Clinical Research. Each meeting lasted an average of two hours and was semi-structured in nature. The Dean shaped the discussion and gave updates from university administration while the faculty gave input focused around course design and structure as well as curriculum content. Approximately four hours was spent participating in these planning meetings, held once a month for two consecutive months, followed by an approximate six hours of analysis and further research clarification on items discussed.

\section{2 | Graduate Program Process Maps}

Semi-structured interviews and document analysis are a means to gain an in-depth understanding of business processes involved at the University Elias et al. (2014). Many of the administrative faculty interviews and discussion during faculty meetings revealed possible inefficiencies in current graduate program processes as well as apprehension surrounding interdisciplinary programs and the management thereof. The challenge in managing these programs alludes to integrated programs attracting more academically innovative students and faculty. As a result, more effort is required from students due to the challenges associated with breadth of expertise and the reliance on student's integration of concepts Bardecki (2015); Gantogtokh and Quinlan (2017). Through the research conducted, seven "milestones" were organized to map out the processes involved in the graduate programs at the University. These milestones consist of: newline

1. Authorization to Plan New Program (Appendix A)

2. Authorization to Establish New Program (Appendix C)

3. Approval of New Degree Program (Board of Governor's Action and University Announcement)

4. Launch of New Graduate Program

5. Admissions and Acceptance of Students

6. Enrollment of Students

7. Program Evaluation

Standard Business Process Model and Notation (BPMN) is utilized to display the processes and are developed in a draw.io (ref, https://draw.io), a free online diagram software that is a Visio online alternative and is the most tightly Google Drive integrated diagramming application available. Using this software allowed for easy, free sharing to necessary stakeholders. Seven horizontal "swim lanes" distinguishing each major unit of job responsibilities at the University are used as notated below:

1. University Administration (Chancellor, Provost, and Deans)

2. University Committees and Advisory Boards

3. System Administration (General Administration, Graduate Council, Board of Governors)

4. University Departments and Faculty (Department Chairs, Graduate Coordinators, Faculty involved with program) 
5. Graduate School Staff

6. Program Director (Administrator in charge of specific graduate program)

As seen in Figure 3, Milestone 1 is the current process in place to gain Authorization to Plan New a Program. This

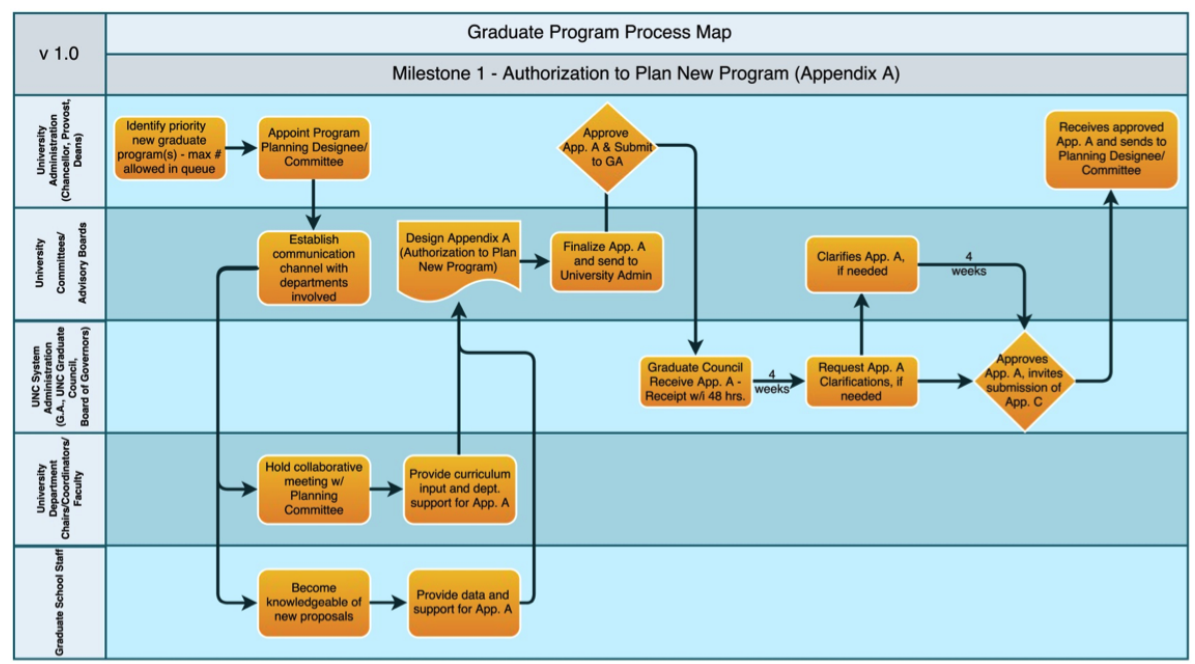

F I GURE 3 Milestone 1, Authorization to Plan New Program

authorization requires a document, Appendix A, which is an application from the university system Policy Manual that requests detailed information about the proposed new program. The first step in starting a new graduate program is to identify the priority programs and which should be considered by the university administration. A maximum of some new programs (typically 3-5) can be in the queue at a given time per the General Administration. The Chancellor approves which new programs will be part of the queue, a responsibility assigned by General Administration. This was the first area found to have the potential for further process detail. Aside from asking Deans for input on new programs, it was unclear what determining factors would be considered to establish the need for new programs and how to prioritize them. The Tennessee Colleges of Applied Technology notes using economic analyses on both a statewide and regional level and input from campus Business and Industry Advisory Boards to determine recommendations for expanding programs that have more favorable job outlooks and starting new programs when a rising job sector does not correspond to an existing academic program Giles (2015). The processes leading up to submitting a finalized version of Appendix A were also found to need clarity in regards to how a Program Planning Designee and Committee is chosen, the involvement of departments and graduate school staff in the design of the document, and the element of time. Clear communication between stakeholders is vital in these planning stages because Appendix $A$ is an intricate document that must be well-thought out in design, representing a program that is unique and meets a clear need in the market to gain approval. This is due to the rigorous process at General Administration, which will often deny proposals that overlap with other existing programs in the university system, with other proposed programs further in their process, or that lack apparent future success. Once Appendix A is finalized and sent to the Graduate Council, the process and timelines are clear and set by the state. At the end of Milestone 1, the University Administration receives Authorization to Plan a New Program. In Milestone 2, Authorization to Establish New Program, an application is also required from the System Policy Manual, Appendix C, which requests further detailed information about the planned program. Figure 4 shows a 
similar pattern as seen in Milestone 1 where the involvement of departments and graduate school staff, assumed to be of larger involvement since approval of Appendix A, is not linear and poses potential for confusion. This confusion can

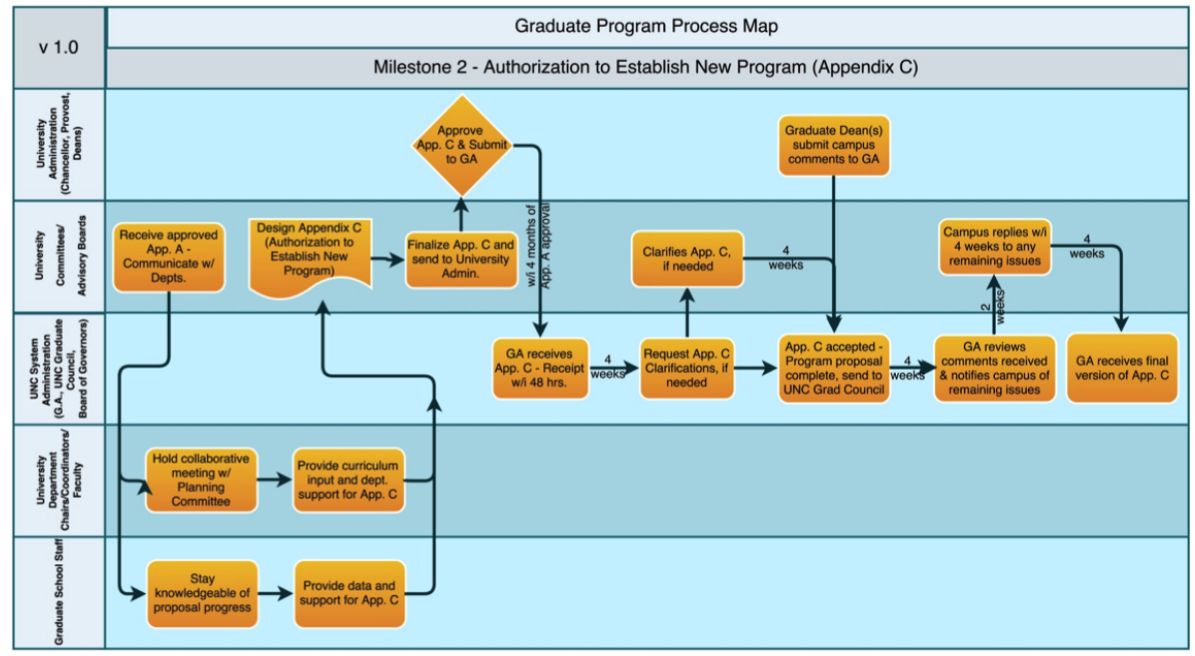

F IG URE 4 Milestone 2, Authorization to Establish New Program

be compounded by the involvement of multiple departments in the case of an interdisciplinary program and under more specific time constraints since Appendix $C$ is required to be submitted within four months of receiving Authorization to Plan. As with Appendix A, once Appendix C is finalized and sent to General Administration, the process and timelines are clear and set by the state. At the end of Milestone 2, General Administration receives the university's final version of the Appendix $\mathrm{C}$ application and then moves through an official approval process. Once the University resolves any issues with Appendix C, General Administration makes a recommendation to the Committee on Educational Planning, Policies, and Programs to approve the new program as seen in Figure 5 - Milestone 35 . Once approved, the Committee presents the approval before the Board of Governors. The Board meets an average of eight times per year. The time of year that Appendix $\mathrm{C}$ is presented to the Board will affect the time elapsed between receiving approval based on the next available meeting. Milestone 3 ends with the university officially announcing the new graduate program and formal steps taken by University administration to appoint Advisory Board(s) (if applicable) and a Program Director. As a future mapping improvement, additional details on how the new program is officially announced along with how advisory board(s) and the Program Director are chosen could provide clarity between Milestones 3 and 4 . In Milestone 4 (Figure 6), the University receives approval and follows through with executing new program processes that first affect the university committees and advisory boards, departments, and faculty, as well as the appointed program director. This is the stage where all planning comes to fruition and actions need to move quickly to meet catalog deadlines and gain approval from the university level Graduate Council before being able to start the admissions application process. Mapping out the processes in Milestone 4 is vital to show that many activities must take place simultaneously, all of which to this point are involved in planning to some degree but in unofficial roles (i.e. Program Director and Advisory Boards) and unable to take true action. It is important for universities to have a strong grasp on the many roles involved in launching a new graduate program and the collaboration needed to meet deadlines. At the end of Milestone 4 , Graduate Council approves all changes to the graduate catalog; the graduate school updates all appropriate sites with the new program information and the program director officially executes the marketing strategy to attract competitive 


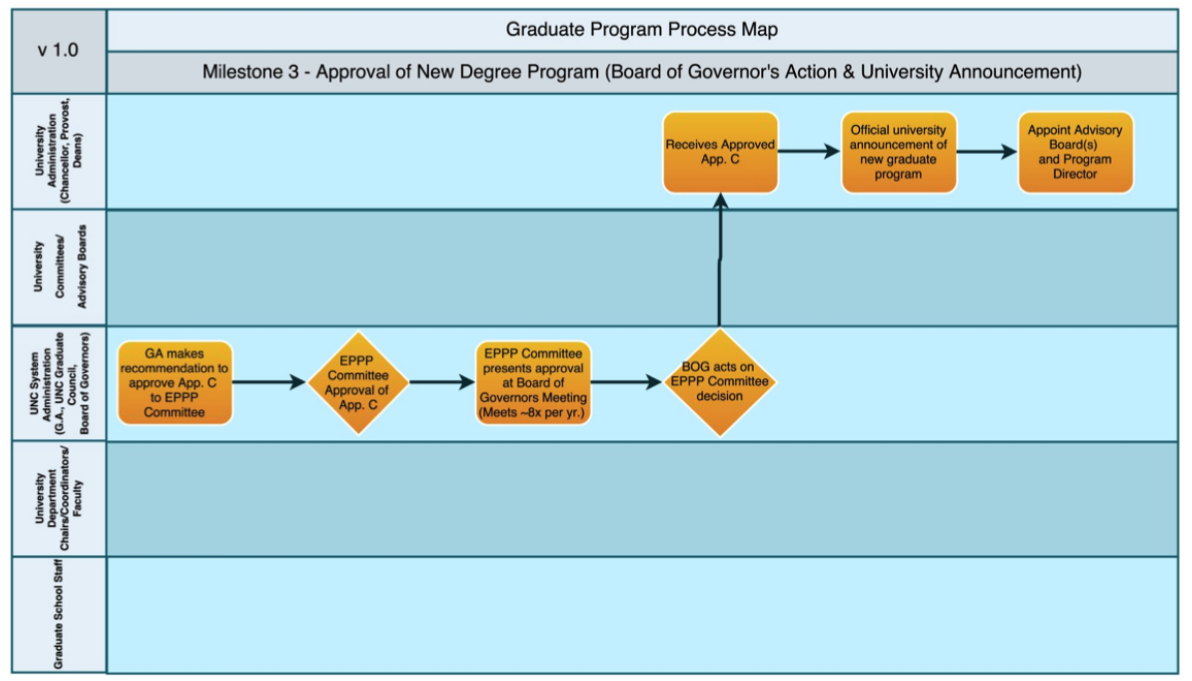

F I GURE 5 Milestone 3, Approval of New Degree Program (Board of Governor's Action and University Announcement)

students. Milestone 5 (Figure 7, is relatively straightforward and linear in its processes and will repeat on an annual basis. When first starting a new program, the time frame between beginning to receive applications and the first day of classes may not feasibly be the 6-9 months shown, although this is ideal and should be routine after year one. Also, of note, while applications are being received and reviewed, the Program Director will execute Assurance of Learning measures and data collection as applicable for this stage in the process as seen in Milestone 7 - Program Evaluation (Figure 9). Assurance of Learning refers to the systematic process of data collection related to student learning outcomes which are imperative to the overall continued effectiveness of the program and should be started as soon as applications are received to help drive future planning decisions. Milestone 5 concludes with notification to students who are accepted into the program, contingent upon meeting pre-requisite requirements. As seen in Figure 8, Milestone 6, the Graduate School receives offers of admissions acceptance from incoming students and the process proceeds with orientation. The Program Director or their designee, depending on program size, works as the point of contact for students and handles relations and advising as needed to ensure program success. The faculty begin teaching courses in this milestone and contribute to the Assurance of Learning process, which coincides with Milestone 7 - Program Evaluation, by collecting data about student learning outcomes used to develop and improve the degree program continuously. Milestone 6 concludes with the retiring of students through graduation from the program. Milestone 7 - Program Evaluation (Figure 9) does not start where Milestone 6 ends off, specifically, but instead begins an overlap with that of Milestones 5 and 6 as mentioned above. Program evaluation is an essential part of the process to ensure the ongoing effectiveness of a graduate program and is often not given the time and attention that is needed. This milestone involves extensive involvement and facilitation by the Program Director who should organize at least an annual "State of the Program" meeting with the teaching faculty and department administration as well as communicate with the Advisory Board(s), if applicable. Any changes to the program, i.e. course structure, faculty positions, and curriculum requires updating the graduate catalog. These change proposals would then revert to the processes in Milestone 4 to gain Graduate Council approval. One of the slowest processes discovered in this research is that of updating the graduate catalog which is required nearly a year in advance of the start of the new school year (October before August fall semester start). This 


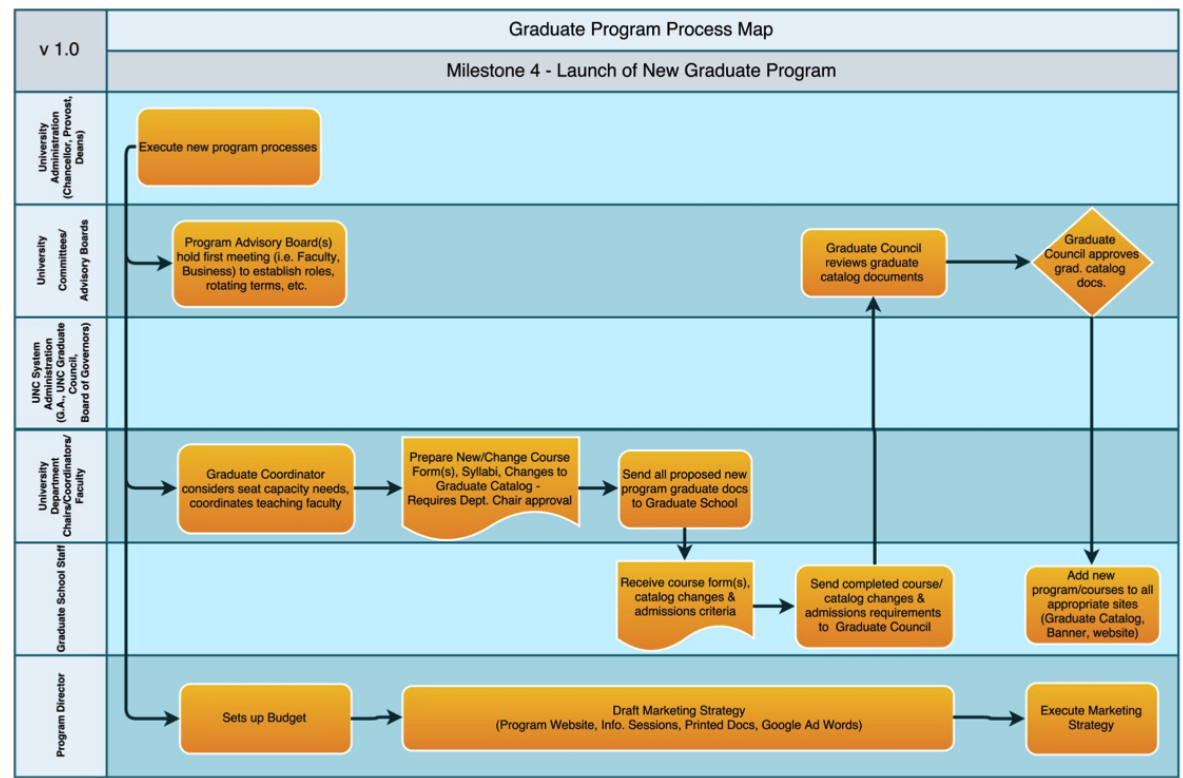

FI GURE 6 Milestone 4, Launch of New Graduate Program

delay intensifies the need for regular program evaluation and poses a potential opportunity for efficiency improvements. Milestone 7 concludes with university administration facilitating a 5-year review of the program to ensure program success, efficiency, and continuous applicability in the job market which satisfies not only requirements at the university and state levels but also that of any specific program accreditations.

\section{5 | CONCLUSIONS}

Business process modeling in higher education can help to provide a flexible roadmap to rethink, redesign, and streamline processes to achieve significant efficiency gains and ultimately lead to sustainable degree programs. This paper applies BPM to a real higher education institution, which is seeking to grow graduate programs and specifically add an analytics degree that meets the staggering market demand for data science professionals. The first goal of this project was to affirm the need and identify the desired analytics skills in the regional market for use in designing a new master's degree program. This was accomplished through semi-structured interviews with area businesses that confirmed the need in the region and helped shape the learning outcomes for graduates of the future degree program. The second goal of this project was to map out the current processes in place to start a new graduate degree program at the University. This was done by interviewing university domain experts to produce seven milestones that showed the responsible parties involved and their binding interactions to ensure communication between departments as needed in an interdisciplinary program. The analysis and mapping of the current processes helped to identify possible areas of inefficiency and highlighted the need for ongoing program evaluation to ensure graduates have skills that continue to meet the needs of the market. These maps can be used as a timeline tool for stakeholders as well as a stepping stone for future analysis and identification of solutions to further streamline higher education processes to allow improved flexibility. Businesses are seeking professionals who are leaders and can fill competency gaps by applying their depth of 


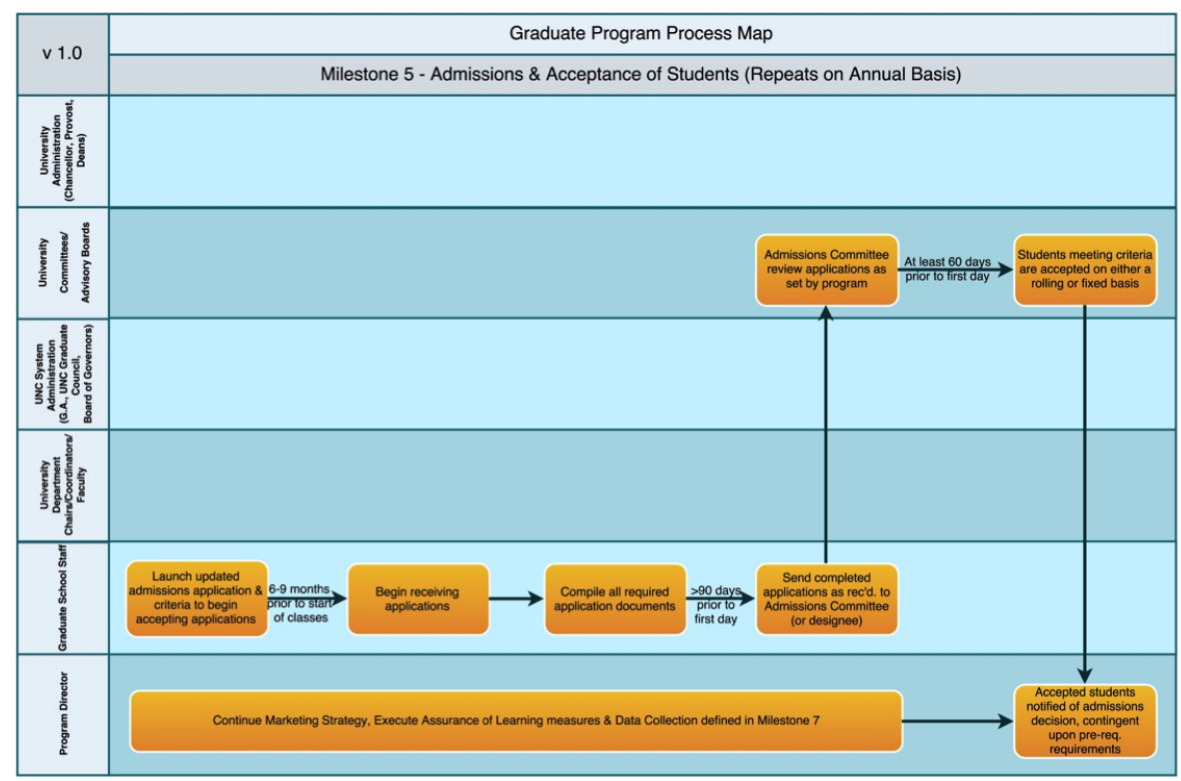

FIGURE 7 Admissions and Acceptance of Students

knowledge to a broad range of challenges that cross multiple departments. Universities must become more nimble in their processes to encourage interaction across departments and disciplines to meet these demands and be innovative without compromising quality.

\section{REFERENCES}

() Gartner Says Technical Aptitude No Longer Enough To Secure Future for IT Professionals. URL: http://www.gartner.com/ newsroom/id/492218.

Abdous, M. and He, W. (2008) A Framework for Process Reengineering in Higher Education: A case study of distance learning exam scheduling and distribution. The International Review of Research in Open and Distributed Learning, 9. URL: http://www . irrodl.org/index.php/irrodl/article/view/535.

Bardecki, M. (2015) Developing and Managing Integrated [Interdisciplinary/Transdisciplinary] Graduate Programs in Environmental Science and Management in a Collaborative Context. In Integrative Approaches to Sustainable Development at University Level, 197-209. Springer. URL: http: //link. springer.com/chapter/10. 1007/978-3-319-10690-8_14.

Cegielski, C. G. and Jones-Farmer, L. A. (2016) Knowledge, Skills, and Abilities for Entry-Level Business Analytics Positions: A Multi-Method Study. Decision Sciences Journal of Innovative Education, 14, 91-118. URL: http://onlinelibrary . wiley . com/doi/10.1111/dsji.12086/abstract.

Chiang, R. H. L., Goes, P. and Stohr, E. A. (2012) Business Intelligence and Analytics Education, and Program Development: A Unique Opportunity for the Information Systems Discipline. ACM Trans. Manage. Inf. Syst., 3, 12:1-12:13. URL: http: //doi.acm.org/10.1145/2361256.2361257.

Davenport, T. H. and Patil, D. J. (2012) Data scientist. Harvard business review, 90, 70-76. URL: http://www. billsynnotandassociates.com.au/images/stories/documents/data_scientist.pdf. 


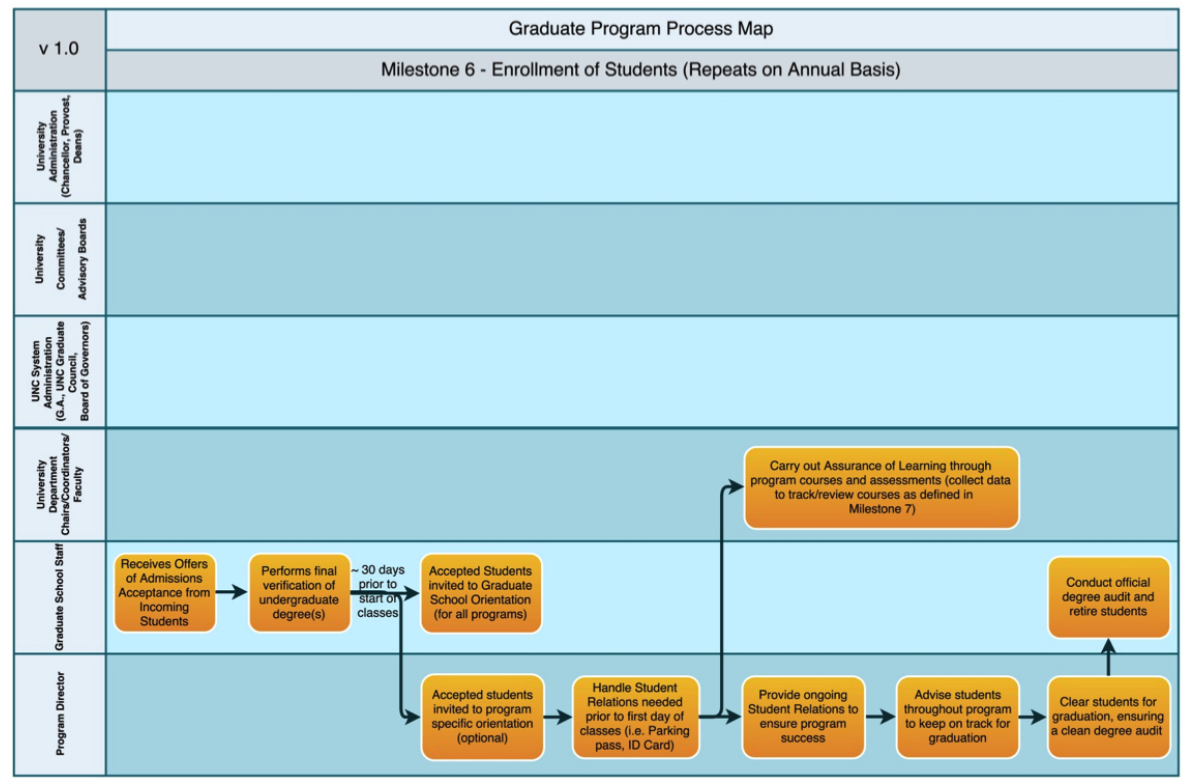

FIGURE 8 Milestone 6, Enrollment of Students

DeSantis, D. and Laudato (2015) Higher Education Process Mapping. URL: https : //focusedunow . com/process-mapping-forenrollment-and-retention-success/.

Drost, D. and Chaney, J. (2014) Core Course Outcomes Assessment and Program Continuous Improvement Using an Integrative Business Plan an Empirical Evaluation. Developments in Business Simulation and Experiential Learning, 28. URL: https://journals.tdl.org/absel/index.php/absel/article/view/799.

Drăgan, M., Ivana, D. and Arba, R. (2014) Business Process Modeling in Higher Education Institutions. Developing a Framework for Total Quality Management at Institutional Level. Procedia Economics and Finance, 16, 95-103. URL: http: //www.sciencedirect.com/science/article/pii/s2212567114007795.

Elias, M., Bider, I. and Johannesson, P. (2014) Using Fractal Process-Asset Model to Design the Process Architecture of an Enterprise: Experience Report. In Enterprise, Business-Process and Information Systems Modeling, Lecture Notes in Business Information Processing, 287-301. Springer, Berlin, Heidelberg. URL: https : //link . springer . com/chapter/10.1007/9783-662-43745-2_20. DOI: 10.1007/978-3-662-43745-2_20.

Gantogtokh, O. and Quinlan, K. M. (2017) Challenges of designing interdisciplinary postgraduate curricula: case studies of interdisciplinary master's programmes at a research-intensive UK university. Teaching in Higher Education, 22, 569-586. URL: http://dx.doi.org/10.1080/13562517.2016.1273211.

Giles, B. W. (2015) The Tennessee Colleges of Applied Technology: integrating academic planning with regional job markets and capital investments. Planning for Higher Education, 43, 82. URL: http://search.proquest.com/openview/ a225a00cb72c1b5147d53f5f5e54d59c/1?pq-origsite $=$ gscholar\&cbl $=47536$.

Gupta, B., Goul, M. and Dinter, B. (2015) Business Intelligence and Big Data in Higher Education: Status of a Multi-Year Model Curriculum Development Effort for Business School Undergraduates, MS Graduates, and MBAs. CAIS, 36, 23. URL: http: //aisel. aisnet. org/cgi/viewcontent. cgi? article=3850\&context=cais. 


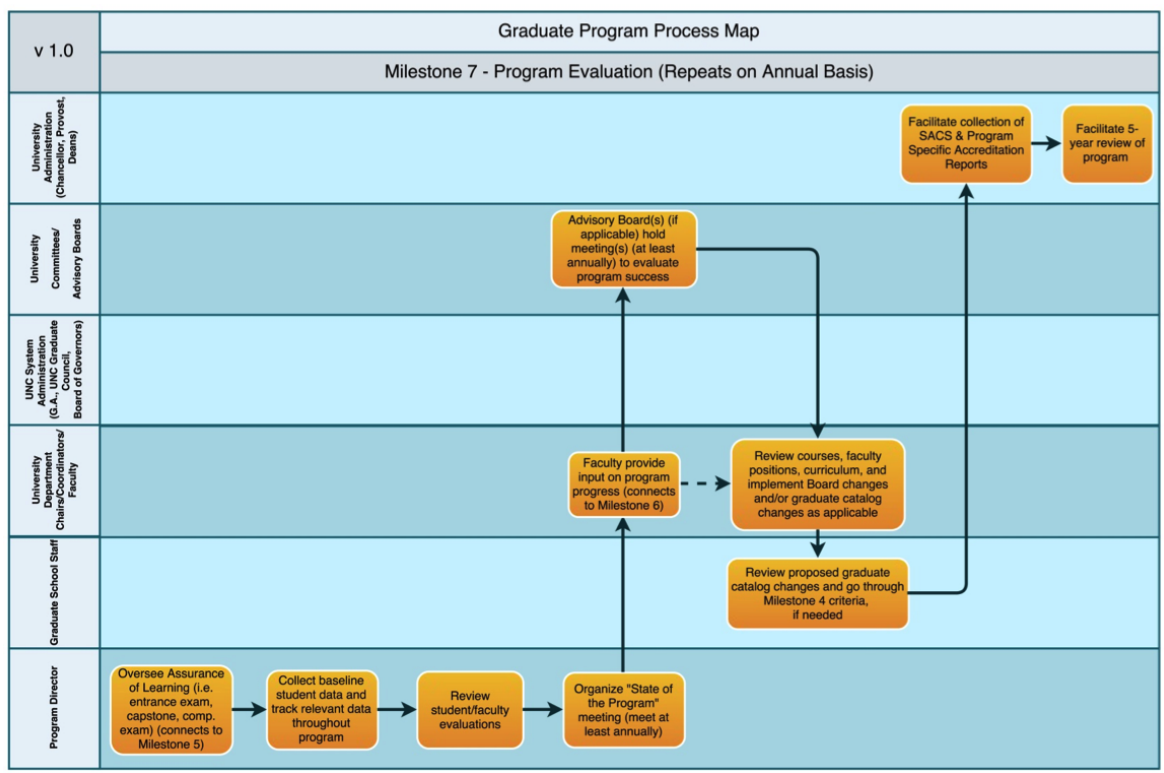

FIGURE 9 Milestone 7, Program Evaluation

Jacobi, F., Jahn, S., Krawatzeck, R., Dinter, B. and Lorenz, A. (2014) Towards a design model for interdisciplinary information systems curriculum development, as exemplified by big data analytics education. URL: http://aisel . aisnet.org/ecis2014/ proceedings/track $11 / 12 /$.

Leshner, A. I. (2015) Rethinking graduate education. Science, 349, 349-349. URL: http://science. sciencemag. org/content/ $349 / 6246 / 349$.

Rappa, M. () Institute for Advanced Analytics. URL: http://analytics .ncsu .edu/?page_id=4184.

Swanson, Z. and Hepner, M. (2011) Knowledge Management ERP Curriculum Design/Mapping (Theory and Development Tools). Decision Sciences Journal of Innovative Education, 9, 209-226. URL: http: //onlinel ibrary · wiley . com/doi/10.1111/ j.1540-4609.2011.00304.x/abstract.

Tremblay, M. C., Deckard, G. J. and Klein, R. (2016) Health informatics and analytics - building a program to integrate business analytics across clinical and administrative disciplines. Journal of the American Medical Informatics Association, 23, 824-828. URL: https://academic . oup.com/jamia/article/23/4/824/2201437/Health-informatics-and-analytics-building-a.

Wang, Y. (2015) Business intelligence and analytics education: Hermeneutic literature review and future directions in is education. Browser Download This Paper. URL: https : //papers . ssrn. com/sol3/papers . cfm?abstract_id=2603365. 